\title{
A memória e o espaço aberto: dinâmicas sensíveis no desenho dos espaços musealizados
}

\section{Memory and open space: sensitive dynamics in the design of musealized spaces}

\author{
Renata Almeida de Melo \\ Siqueira \\ Mestranda do Programa de \\ Pós-Graduação em Desenho \\ Cultura e Interatividade da \\ Universidade Estadual de \\ Feira de Santana \\ renatamelodesign@gmail.com
}

\section{RESUMO:}

Este trabalho objetiva-se em defender a ideia de que espaços abertos são fonte de expectativas sensíveis, se desenvolve a partir de conceitos que envolvem memória e o processo de musealização dos espaços, colocando estes como objeto principal para difusão e aproximação de público para questões sociais, destacando a sensibilidade impressa nos espaços.

Palavras-chave: musealização; espaço; memória.

\section{ABSTRACT:}

This work aims to defend the idea that open spaces are a source of sensitive expectations, develops from concepts that involve memory and the process of musealization of spaces, placing them as the main object for dissemination and approximation of public to social issues.

Keywords: musealization; space; memory. 


\section{MUSEALIZAÇÃO E SUA DINÂMICA}

Conectar-se ao passado já não está como um dos aspectos principais das funções dos museus contemporâneos, novos conceitos e novas tecnologias, ligam os caminhos a serem desenhados em suas mudanças sociais, expectativas, acerca dos sentimentos e respostas. Os espaços e objetos musealizados, contam com uma carga intrínseca aos mesmos, que permitem este fato. Dentro da perspectiva científica, que influenciou amplamente o Comitê Internacional de Museologia - ICOFOM nos anos 1980 a 1990, apresenta a Museologia como o estudo de uma relação específica entre o homem e a realidade, estudo no qual o museu, fenômeno determinado no tempo, constitui uma das materializações possíveis.

Para Stránský, a Museologia apresenta características de uma disciplina científica independente, cujo objeto de estudo é uma atitude específica do Homem sobre a realidade. A defesa de que o homem caminha sobre a valorização das coisas e lugares para contar histórias e dar novos sentidos, podem permitir o processo de musealização de determinados espaços, para a preservação da memória e para construção de saberes e vivências sociais, já que, retornando ao pensamento de Stránský , a atitude do homem surge como objeto, para isso, é possível pensar que o espaço aberto, ou espaço público, que possua uma carga de expressões da memória, talvez em sua categoria de valorização social se torne espaço musealizado.

Cabe advertir, entretanto, que se tudo é musealizável, nem tudo é museu. Segundo Stránský $(1985,97)$, a condição de um objeto de museu é determinada pela relação objeto - sujeito, que não existem isoladamente, mas apenas como "parte de uma realidade natural e social". Visto que o desenho urbano é predeterminante para as ações do homem no espaço, rocha, (pag.06) faz uma relação entre museu instituição e espaços abertos, o museu como um lugar de memória, que produz sensações nas pessoas, que questiona o lugar de estar, o de passagem. Já os espaços com as atividades dos agentes sociais. A produção cartográfica a partir da experiência. Constituindo uma cartografia sensível da função dos espaços urbanos, em uma determinada cidade, acelerada, em constante transformação, atravessado pela memória institucionalizada, as cartografias sensíveis apresentadas na teoria da Geografia e Arquitetura aproximasse da dinâmica da Musealização, ambas se conectam por toda experiência dos sujeitos no espaço, sabendo que as mudanças são reflexo dos processos.

Para Loureiro:

...a musealização consiste em um conjunto de processos seletivos de caráter info-comunicacional baseados na agregação de valores a coisas de diferentes naturezas às quais é atribuída a função de documento, e que por esse motivo tornam-se objeto de preservação e divulgação. Tais processos, que têm no museu seu caso privilegiado, exprimem na prática a crença na possibilidade de constituição de uma síntese a partir da seleção, ordenação e classificação de elementos que, reunidos em um sistema coerente, 
representarão uma realidade necessariamente maior e mais complexa Loureiro (2011).

Fazendo comparações entre pontos diferentes das citações, relacionando com a sociedade, ALMEIDA (1996,pag107) destaca que: Podemos facilmente fazer um paralelo com o alargamento da noção de objeto para a nova museologia, pois ambas pretendem abarcar tudo o que diz respeito ao homem, não privilegiando raças, culturas, formas de estar, mas considerando que tudo pode ser musealizado e objeto de estudo do historiador, e pesquisador. O diálogo dos espaços públicos segue o curso da multiplicidade. Estas são extensões que reafirmam espaços públicos construídos para, pela e com a ética da multiplicidade (DELEUZE, 1997).

\section{ESPAÇOS ABERTOS E MEMÓRIA}

Na segunda metade deste século, os museus, tanto americanos como europeus, começam a se preocupar e a incorporar as lutas pela preservação do meio ambiente. 0 conceito de patrimônio é revisto e ampliado, englobandose o meio ambiente, o saber e o artefato.

Retornando ao processo do novo olhar sobre o serviço do museu para o homem, a IX Conferência Geral do ICOM, realizada em Paris e Grenoble, em 1971, por exemplo, teve como tema principal "O Museu a Serviço do Homem. Atualidade e Futuro". Vários pontos foram levantados como referenciais que apontavam para a existência de uma crise nos museus, sobretudo em relação ao seu envolvimento com o público, notadamente o seu distanciamento dos problemas sociais.

A Mesa Redonda realizada em Santiago do Chile, em 1972, e considerada como um marco no processo de transformação da museologia, sobretudo, por ter colocado em evidência a prioridade da ação museal no campo da intervenção social, abrindo espaço para um repensar global da museologia, diante disso, discorre Santos, colocando em evidência a nova museologia, como abertura para a interdisciplinaridade a serviço da sociedade e seus problemas, servindo de alerta e promovendo novos valores acerca de tudo que envolve o contexto do "homem".

\footnotetext{
"Os museus devem deixar de ser passivos colecionadores, para se tornarem participantes ativos nas transformações da sociedade. Eles não devem simplesmente empregar novos métodos, mas devem ser um novo intermediário destemido, encarando de frente os problemas complexos e crescentes, como o racismo, o crescimento material, a pobreza, a carência de habitação, desemprego, drogas, deterioração das cidades, planejamento urbano, educação, todos os aspectos relativos à existência humana procurando encontrar as respostas. Santos,(1996 pag.46).
}

Essa nova visão, faz com que as discussões em torno da preservação sejam retomadas, contribuindo para o surgimento de novas categorias de museus e para a construção de pressupostos museológicos, até então desconhecidos. Santos (1996) Para tal discussão, é conveniente dar exemplos 
dos memoriais1, como o memorial e museu 11 de setembro, situado em Nova York.

Figura 1: Imagem 3D interior do museu 11 de setembro.

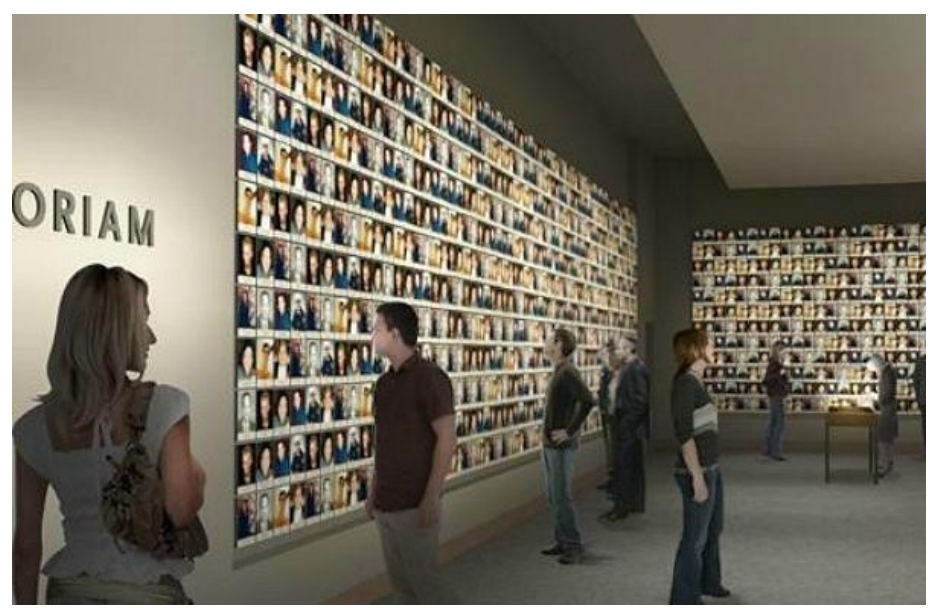

Fonte:Nova-york-museu-11-setembro.

Figura 2: Imagem exterior do museu 11 de setembro.

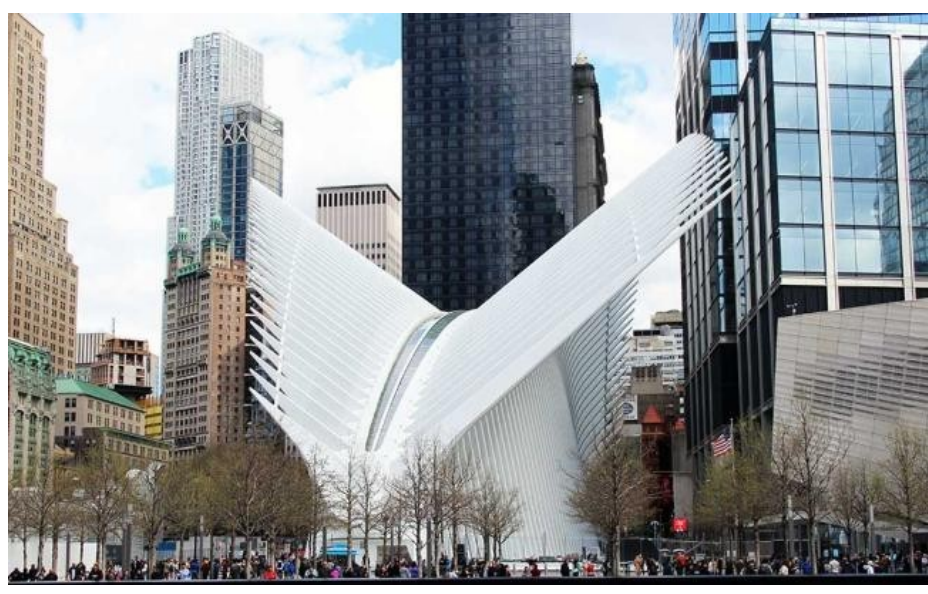

Fonte:Nova-york-museu-11-setembro

E ainda, mais próximo do contexto brasileiro, o Memorial em homenagem às vítimas do rompimento da barragem em Brumadinho- MG, ainda com intenção de inserir o tema da memória, podemos destacar as experiências de caráter apreciativo e gerador de novas expectativas, destacando o museu do amanhã na figura 3 ,que abarca em sua estrutura elementos naturais, como a água com temáticas também acerca da preservação ambiental, não deixando de lado os avanços tecnológicos e urbanizações das cidades.

\footnotetext{
1 Denominação atribuída ao monumento edificado em homenagem ou lembrança de algum indivíduo ou de determinado acontecimento, Designação da narração de acontecimentos ou pessoas que são inesquecíveis - memoráveis;
} 
Figura 3: Imagem área Museu do Amanhã - RJ.

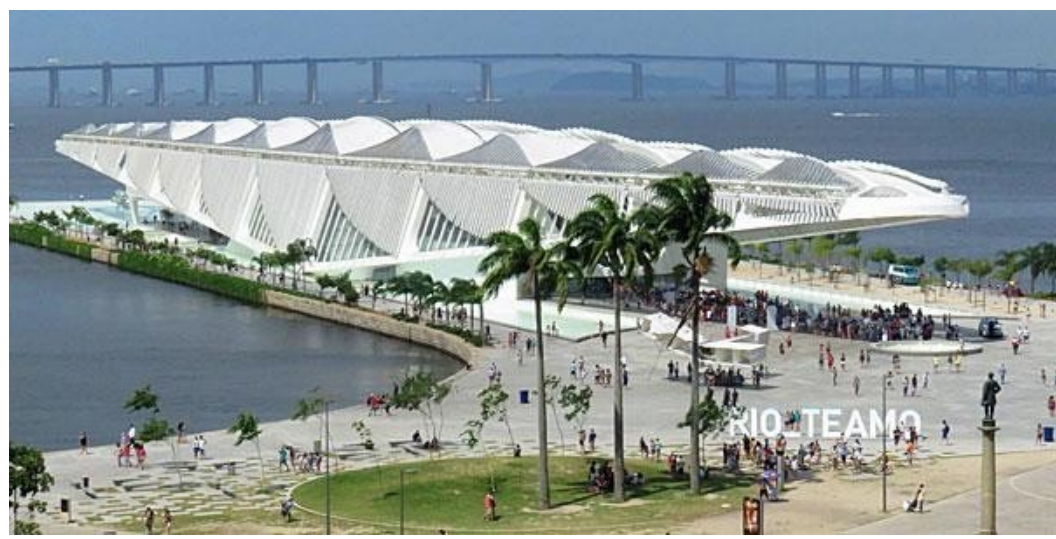

Fonte: Museu do amanhã/Divulgação Internet, 2021

Referência também ao maior museu a céu aberto Do mundo que também está localizado em Brumadinho-MG (INHOTIM), fazendo uma interação com elementos da arte contemporânea, da natureza ,da arquitetura ,do desenho e de tantos outros campos de interesse interdisciplinar, que os espaços musealizados se conectam.

Figura 4: Vista aérea do Instituto Inhotim.

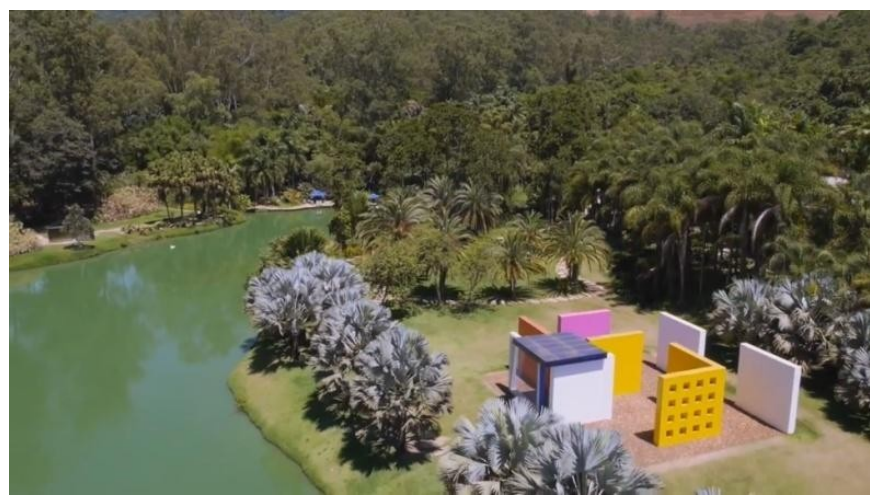

Fonte: Reprodução/CNN (24.set.2020)

Este é o desenho da nova museologia e de tudo que envolve as ciências sociais, nada mais dinâmico do que as ações humanas para dar rumos diferentes aos estudos interdisciplinares, para construir novas memórias. 0 processo de urbanização de uma cidade gera sentimentos múltiplos acerca do futuro e seu passado, destaca-se por ações de interesse pessoal e social que culminam em experiências distintas e regadas de história.

[...] portanto, atentar para as mediações significativas que permeiam a apreensãoda cidade, de seus lugares, da dinâmica das relações sociais; compreender as formas de circulação pelo espaço urbano, e de vinculação com os diferentes lugares deste espaço. São aspectos que me parecem cruciais para uma abordagem das relações entre modernidade, cidade e sensibilidades, temas estes que se entrelaçam com as questões da memória e dos processos de constituição dos sujeitos. HADLER, (2015 p 84 ). 
Perceber a cidade e suas possibilidades múltiplas de usufruir e modelar o espaço urbano, a depender da necessidade de cada usuário, faz com que o espaço da musealização se amplie, principalmente pelo repertório vivido de cada indivíduo.

\section{CONSIDERAÇÕES FINAIS}

0 processo de urbanização em que os espaços de periferias e os espaços dos grandes centros podem imprimir a mesma carga histórica e representatividade, cada espaço estando ligado a comunidade e sua utilização, podendo ser musealizado, referenciando as demandas de preservação e seu fim educacional, abrangendo questões sociais resultando na resolução de problemas, reflexão sobre os mesmos e até apreciação da natureza e preservação de elementos ou do todo. como cita LE GOFF, (2004).

A memória no homem faz intervir não só a ordenação de vestígios, mas também a releitura desses vestígios, na maneira como é exposto, apresentado a comunidade. É pertinente considerar que os diálogos propostos aqui, são de reflexão sobre os caminhos da dinâmica da musealização, sobre os espaços urbanos e de preferência sobre os lugares que possuem uma abrangência significativa em relação aos problemas sociais atuais. É possível CONSIDERAR que, em processos de mudanças estéticas, existem mudanças históricas, existem mudanças sociais, mudanças de atitudes do homem que podem ir além das funções de rotina, hábitos e crenças. No espaço aberto as relações do homem em sociedade, faz uma conexão com histórias particulares, permite sentir a cidade como troca de saberes, diálogos nos bancos das praças, vistas a paisagem natural ou até monumentos afixados que relembram a história, a rotina do trabalhador que segue sempre o mesmo caminho, as crianças que utilizam o parque infantil, as pessoas que fazem atividades físicas e as que visitam o espaço. A musealização é contudo, um processo de sensibilidade, entendendo as demandas sociais e colaborando para a preservação da memória desses espaços em sua complexidade.

\section{REFERÊNCIAS}

HADLER, Maria Sílvia Duarte.Cidade, Memórias e Sensibilidades - p. 81-94

Resgate - vol. xxiii, n.29 - jan./jun. 2015

ARAÚJO, Guilherme e PEREIRA, Anete Memória e espaço público: reflexões sobre a praça Wandyck Dumont em Bocaiuva/MG e as suas reformas ao longo do tempo, 2019

SEEMANN, Jörn ,2003 .0 espaço da memória e a memória do espaço.

FERREIRA ,Carlos /SOUZA Adriana / PINHEIRO Sandra História e memória: tecendo caminhos do documentário Os Guardiões da Lagoa. 
SANTOS, Maria Célia, Uma abordagem museológica do contexto urbano. CADERNOS DE MUSEOLOGIA № 5 - 1996

ALMEIDA, Maria Mota, Mudanças Sociais / Mudanças Museais Nova Museologia/Nova História - Que relação ? /cadernos de museologia no 5 1996.

NIEMEYER ,Maria Lucia Documento e musealização: entretecendo conceitos Museus e estudos interdisciplinares 2013.

STRÁNSKÝ, Zbyn`ek Z. Predmet muzeologie. / (ed.). Sborník materiálu prvéhomuzeologického symposia/ Bruno: Museu da Morávia, 1965. pp. 30-33

ROCHA, Eduardo / Cartografias sensíveis na cidadeExperiência e resistência no espaço público da Região Sul - RS.

DELEUZE, G.; GUATTARI, F. Mil Platôs. v.1. Rio de Janeiro: Ed. 34 Letras, 1995. 